\title{
TRABALHO INFANTIL ARTÍSTICO E AS CONSEQUÊNCIAS DO PALCO: BASTIDORES QUE NINGUÉM MOSTRA
}

\author{
Rosicleia Palitot da Silva ${ }^{1}$ \\ Gilmara Jacinto Seixas ${ }^{2}$ \\ Julia Nunes Pereira ${ }^{3}$ \\ Elle Beethoven dos Santos Resende 4 \\ Adilson Pereira da Silva Júnior ${ }^{5}$
}

RESUMO: A infância é uma construção social balizada por questões culturais, filosóficas, econômicas e religiosas, perpassando por fases, nas quais podem sofrer violações dos seus direitos. $O$ trabalho infantil tem crescido em todo o mundo, não sendo diferente no contexto brasileiro. Esse tipo de trabalho demonstra uma violação aos direitos humanos da fase infanto-juvenil. Embora exista mecanismos legais que tem a pretensão de erradicar este tipo de exploração, ao redor do mundo milhões de crianças e adolescentes continuam a ser submetidos a atividades laborais impróprias a sua faixa etária, tendo por consequência o comprometimento de seu pleno desenvolvimento físico, intelectual e social. Frente a isto, o presente artigo objetivou analisar à luz do ordenamento jurídico brasileiro qual o entendimento acerca do trabalho infantil artístico de criança e/ou adolescente. Essa obra foi desenvolvida mediante o estudo de bibliografia atualizada voltada à temática do trabalho infantil, trabalho infantil artístico e desenvolvimento humano infanto-juvenil. As obras estudadas apontam para a complexidade do problema, que não leva em consideração como a pressão exercida pelas câmeras e holofotes impactam o bem-estar de uma criança, a visão que esta possui de si, de seu corpo e seu papel na massa social e em sua família, atribuindolhe responsabilidades que são além de sua idade. Ademais, observou-se a necessidade de uma regulamentação mais específica e efetiva quanto ao trabalho infantil artístico, para evitar a exploração destes menores de idade e os efeitos decorrentes de tal exploração, como o abandono escolar, danos psicológicos, físicos e problemas de autoimagem entre outros.

Palavras-chave: trabalho infantil artístico. Desenvolvimento infantil. Constituição. ECA.

\footnotetext{
I Especialista em Psicomotricidade e Neuropsicopedagogia (UCAM), Psicopedagoga de formação e bacharelanda em Direito pela UFPB, e-mail para contato: rosicleiapalitot@gmail.com.

${ }^{2}$ Educadora Física e bacharelanda em Direito pela UFPB, e-mail para contato: gilmaraseixas@gmail.com.

${ }^{3}$ Bacharelanda em Direito pela UFPB, e-mail para contato: julianunesp99@gmail.com

4 Mestre em Ciências das Religiões pela UFPB, historiador de formação e bacharelando em Direito pela UFPB, e-mail para contato: elle.beethoven@gmail.com

5 Especialista em Gestão Pública pela UCAM, e Tecnólogo em Processos Gerenciais e licenciando em Ciências das Religiões pela UFPB, e-mail para contato: adilsonpsjunior@gmail.com.
} 
ABSTRACT: Childhood is a social construction guided by cultural, philosophical, economic and religious issues, going through phases, in which they may suffer violations of their rights. Child labor has grown worldwide, and it is no different in the Brazilian context. This type of work demonstrates a violation of the human rights of children and adolescents. Although there are legal mechanisms that aim to eradicate this type of exploitation, around the world millions of children and adolescents continue to be subjected to work activities that are inappropriate for their age group, with the consequence of compromising their full physical, intellectual and Social. In view of this, this article aimed to analyze, in the light of the Brazilian legal system, what is the understanding about the artistic child labor of children and / or adolescents. This work was developed through the study of updated bibliography on the theme of child labor, artistic child labor and human and child development. The works studied point to the complexity of the problem, which does not take into account how the pressure exerted by the cameras and searchlights impact a child's well-being, the child's view of himself, his body and his role in the social and in your family, assigning you responsibilities that are beyond your age. In addition, there was a need for more specific and effective regulation regarding artistic child labor, to avoid the exploitation of these minors and the effects resulting from such exploitation, such as school dropout, psychological and physical damage and problems with self-image among others.

Keywords: artistic child labor. Child development. Constitution. ECA.

\section{INTRODUÇÃO}

O campo do desenvolvimento humano constitui-se do estudo científico de como as pessoas mudam, bem como das características que permanecem razoavelmente estáveis durante toda a vida. O desenvolvimento humano tem ocorrido, evidentemente, desde que os seres humanos existem, mas seu estudo científico formal é relativamente novo (PAPALIA; FELDMAN, 2013).

De acordo com Almeida (20II), a infância é uma construção social balizada por questões culturais, filosóficas, econômicas e religiosas. $\mathrm{Na}$ idade média a criança era considerada um adulto em miniatura. No século XVII, a infância passou a ter a acepção mais moderna do termo, como um ser essencialmente diferente do adulto. No século XIX, com o advento da Revolução Industrial, a criança voltou a viver precocemente como um adulto (CARVALHO, 2004). Nesse período ocorreu o ápice da exploração dos trabalhadores, mormente crianças e adolescentes, o que ocasionou a eclosão de movimentos sociais e a elaboração das primeiras leis relacionadas à idade mínima para o trabalho. No século XX, após a Primeira Guerra Mundial, adultos passaram a assumir novamente os postos de trabalho antes ocupados por crianças e adolescentes, que perderam o seu valor econômico. Surgiram, então, políticas públicas de preservação e valorização da saúde, educação e moral das crianças e adolescentes (MENNA, 2010).

O trabalho infantil é realizado por pessoas que estejam abaixo da idade permitida para iniciar práticas trabalhistas. Cada país tem sua idade mínima fixada como regra. Conforme Renato Eliseu e Marcelo Boscoli (2020) há 30 anos o Brasil fez uma escolha que mudou os rumos da política pública da infância e adolescência em nosso país, promulgando aquele que seria, e ao nosso ver ainda é, a mais importante legislação infraconstitucional do país: O Estatuto da Criança e do Adolescente - ECA. Um compêndio 
com todos os direitos dessa população, mas também com todas as responsabilidades dos governos, das famílias e da sociedade para com esses "novos cidadãos".

Sabe-se que no Brasil o trabalho realizado por crianças e adolescentes sob o pressuposto de trabalho infantil artístico mostra-se fortemente problemático, enquanto que por um lado a glamourização deste tipo de trabalho diante da possibilidade da criança se tornar uma celebridade é um fator bastante atrativo, por outro ângulo esta continua sendo uma forma de labor infantil e frente a isto, surge o seguinte questionamento: qual o entendimento acerca do trabalho infantil artístico de criança e/ou adolescente à luz do ordenamento jurídico brasileiro?

Diante à problemática apresentada, temos como objetivo geral analisar à luz do ordenamento jurídico brasileiro qual o entendimento acerca do trabalho infantil artístico de criança e/ou adolescente. Especificamente compreender as mudanças ocorridas no ordenamento jurídico brasileiro no que diz respeito ao trabalho infantil; pontuar as produções acadêmicas/cientificas nas questões de trabalho infantil doravante denominadas de trabalho infantil artístico.

$O$ atual estudo mostra-se relevante e se justifica na medida em que busca dar visibilidade e suscitar discussões em relação ao trabalho infantil artístico e suas consequências, para o desenvolvimento sejam elas educacional, físico-motora, intelectual ou biopsicossociais (COSTA; SOUZA; KRIST, 2015) das crianças e/ou adolescentes.

No tocante ao tema, destacam-se as condições a que são submetidas as crianças e adolescentes que sonham em ingressar no mundo artístico. O que elas sentem, as pressões que enfrentam durante as seleções de candidatos, a frustração de não ser selecionados e se sentir excluídos, a pressão durante as gravações e exibições durante o trabalho ao vivo, as extensas jornadas e os prejuízos na frequência e rendimento escolar, afetam um grande número de crianças e adolescentes no Brasil.

Nos dias atuais é comum essas crianças serem incentivadas pelos pais e/ou responsáveis a exercerem trabalhos artísticos motivados pelo retorno financeiro. Em razão do exposto, tendo em vista a fase de desenvolvimento físico e intelectual das crianças e adolescentes é necessário respeitar essa fase, já que a mesma passa muito rápido e se não for vivenciada com suas prerrogativas pode gerar sequelas irreparáveis nas fases seguintes. E muitos dos pais e/ou responsáveis não têm conhecimento acerca da temática e nem a mídia retrata tais assuntos, por isso, é importante fomentar discussões sobre o tema.

\section{DESENVOLVIMENTO}

\section{I Desenvolvimento Humano}

$\mathrm{Na}$ perspectiva sócio-histórica, o desenvolvimento humano é entendido como um processo de internalização de regras, de valores e de modos de pensar e de agir que ocorre nas interações sociais das quais o sujeito participa em seu dia-a-dia (CAMPOS; FRANCISCHINI, 2003, p.122), entre essas interações pode-se mencionar o brincar, que na percepção de Vygotsky (1998) o brincar é uma atividade social da criança, cuja natureza e origem específica seriam elementos fundamentais para o desenvolvimento cultural, ou seja, o brincar como compreensão da realidade. Para o autor, o brinquedo é o principal meio de desenvolvimento cultural da criança. $O$ brincar atua nas zonas de desenvolvimento 
proximal e real da criança. É no brincar que a criança se comporta, além do seu comportamento habitual, diário, vivenciando desafios e situações novas.

De acordo com os estudos de Jean Piaget (I896-1980) o crescimento intelectual é um processo de adaptação ao mundo, e que pode ocorrer por meio do que ele chamou de "assimilação", "acomodação" e "equilíbrio". Para Piaget durante o processo de assimilação, a criança utiliza um esquema já existente para lidar com um novo objeto ou situação, ou seja, uma criança de dois anos vê um figo, mas anteriormente ela apenas conhecia o que era uma maçã. Ao ver uma fruta com formato parecido, a criança irá pensar que o figo também é uma maçã. Já no processo de acomodação, acontece quando a criança não consegue assimilar a informação em um esquema já existente, então ela precisa alterá-lo, ou criar um novo esquema. Ainda com o exemplo mencionado, quando a mãe ou responsável da criança explica que apesar do formato e cor parecidos, aquela é uma fruta diferente, a criança então irá reorganizar o seu esquema sobre "maçã", sabendo agora da existência de outras frutas. No que diz respeito ao equilíbrio, Piaget revela que quando os esquemas existentes de uma criança são capazes de explicar o que ela percebe ao redor, diz-se que ela está em um estado de equilíbrio. No entanto, quando novas informações não podem ser encaixadas em esquemas existentes, ela entra em um incômodo estado de desequilíbrio. Sendo assim, por não gostar da situação de frustração, ela vai sempre procurar restaurar o equilíbrio, dominando o novo desafio.

Durlei de Carvalho Cavicchia (2010, p.II) interpretando as fases do desenvolvimento de Piaget, relata que entre dois e cinco anos, aproximadamente, a criança adquire a linguagem e forma, de alguma maneira, um sistema de imagens. Entretanto, a palavra não tem ainda, para ela, o valor de um conceito; ela evoca uma realidade particular ou seu correspondente imagístico. Tendo que reconstruir o mundo no plano representativo, ela o reconstrói a partir de si mesma. O egocentrismo intelectual está no auge no decurso dessa etapa. A dominação do pensamento por imagens encerra a criança em si mesma.

Segundo a autora, o pensamento imagístico egocêntrico, característico desta fase, pode ser observado no jogo simbólico, no qual a criança transforma o real ao sabor das necessidades e dos desejos do momento. $O$ real é transformado pelo pensamento simbólico, na medida em que o jogo se desenvolve, ao sabor das exigências do desejo expresso no e pelo jogo. É por isso que Piaget considera o jogo simbólico como o egocentrismo no estado puro.

Para Piaget, é por volta dos sete anos de vida que a atividade cognitiva da criança se torna operatória, com a aquisição da reversibilidade lógica. A reversibilidade aparece como uma propriedade das ações da criança, suscetíveis de se exercerem em pensamento ou interiormente. O domínio da reversibilidade no plano da representação, a capacidade de se representar uma ação e a ação inversa ou recíproca que a anula, ajuda na construção de novos invariantes cognitivos, desta vez de natureza representativa: conservação de comprimento, de distâncias, de quantidades discretas e contínuas, de quantidades físicas (peso, substância, volume, etc). O equilíbrio das trocas cognitivas entre a criança e a realidade, característico das estruturas operatórias, é muito mais rico e variado, mais estável, mais sólido e mais aberto quanto ao seu alcance do que o equilíbrio próprio às estruturas da inteligência sensório-motora.

Isto posto, compreende-se que a criança que exerce um trabalho artístico nesta fase, principalmente os de representação, podem desenvolver grande dificuldade de fazer a separação entre o que é real e o que é a representação, já que ela tem que decorar falas, expressar sentimentos e emoções que ela pode ou não vivenciar. Diferente das expressões 
realizadas no ato do brincar em que a criança escolhe o que vai falar ou interpretar, mas o faz por vontade própria e não por coação.

Para Costa, Souza e Krist (2015) O trabalho infantil surge como uma forma de desigualdade e, para as famílias, surge como "necessidade" que cumpre um duplo papel: auxilia no sustento do grupo familiar e "educa" para a vida adulta (MARCHI, 2013). Scarton (2014) afirma que o trabalho infantil traz danos nos aspectos social, econômico, escolar e psicológico, sendo que a partir do momento que a criança se sente obrigada a assumir a responsabilidade do trabalho ela perde sua inocência, constituindo assim a perda da mais tenra infância.

\subsection{O que a Legislação Brasileira diz sobre o assunto?}

No ordenamento jurídico brasileiro a começar pela Carta Magna que adota as normas estabelecidas pela Convenção dos Direitos da Criança (1990), nas quais constam que o trabalho infantil é ilegal. A Constituição Federal em seu Artigo 32 fixa as seguintes obrigações: "Os Estados Partes reconhecem o direito da criança de estar protegida contra a exploração econômica e contra o desempenho de qualquer trabalho que possa ser perigoso ou interferir em sua educação, ou que seja nocivo para sua saúde ou para seu desenvolvimento físico, mental, espiritual, moral ou social” (BRASIL, 1988).

De acordo com o Art. 227 da Constituição Federal (BRASIL, 1988) "é dever da família, da sociedade e do Estado assegurar à criança e ao adolescente, com absoluta prioridade, o direito à vida, à saúde, à alimentação, à educação, ao lazer, à profissionalização, à cultura, à dignidade, ao respeito, à liberdade e à convivência familiar e comunitária, além de colocá-los a salvo de toda forma de negligência, discriminação, exploração, violência, crueldade e opressão". Desta forma, na Constituição Federal em seu Art. $7^{\circ}$ e inciso 33 fica estabelecida a proibição de qualquer trabalho, a pessoas com idade inferior a 16 (dezesseis) anos, salvo na condição de aprendiz, a partir dos 14 (quatorze) anos, sendo resguardado pela Lei do Aprendiz (Lei no 10.097 , de 19 de dezembro de 2000).

De acordo com Estatuto da Criança e do Adolescente - ECA (Lei no 8.069/9o), em seu Artigo $2^{-}$traz uma definição do que considera como criança e adolescente. "Art. $2^{-}$ Considera-se criança, para os efeitos desta Lei, a pessoa até doze anos de idade incompletos, e adolescente aquela entre doze e dezoito anos de idade. Parágrafo único. Nos casos expressos em lei, aplica-se excepcionalmente este Estatuto às pessoas entre dezoito e vinte e um anos de idade" (BRASIL, I990).

No seu Artigo $4^{\mathrm{o}}$ o Estatuto vai reproduzir uma parte do artigo 227 da nossa Constituição Federal, que estabeleceu o princípio da proteção integral da criança e do adolescente. Art. $4^{\mathrm{o}}$ "É dever da família, da comunidade, da sociedade em geral e do poder público assegurar, com absoluta prioridade, a efetivação dos direitos referentes à vida, à saúde, à alimentação, à educação, ao esporte, ao lazer, à profissionalização, à cultura, à dignidade, ao respeito, à liberdade e à convivência familiar e comunitária".

No que diz respeito ao trabalho, o Estatuto discorre em seu Artigo 6o que é proibido qualquer trabalho a menores de quatorze anos de idade”. Com a Emenda Constitucional de 98, ficou estabelecida a proibição de trabalho noturno, perigoso ou insalubre a menores de dezoito e de qualquer trabalho a menores de dezesseis anos, salvo na condição de aprendiz, a partir de quatorze anos. O ECA não incorporou a alteração, mas a Constituição Federal, que está no topo da hierarquia das leis, é o que prevalece. 
Em seu Artigo 6I discorre que "a proteção ao trabalho dos adolescentes é regulada por legislação especial, sem prejuízo do disposto nesta Lei". Sobre isto, a Consolidação das Leis do Trabalho - CLT (BRASIL, 2017), entre os artigos 402 e 44I, estabelece as condições para a atuação profissional de jovens de 14 a 17 anos no Brasil. E inclui redações dadas por outros textos legais, como a Lei do Aprendiz (I0.097/2000) e o decreto federal 5.598/2005.

Destarte, apesar dessa proibição se entender a todas as formas de trabalho, com relação ao trabalho infantil artístico, existe uma interpretação mais flexível que permite o trabalho em empresas circenses, como também na produção, composição, entrega ou venda de escritos, impressos, cartazes, desenhos, gravuras, pinturas, emblemas. Também trabalham em empresas de comunicação, especialmente a televisão e o cinema, que contratam crianças com idade inferior à prevista na legislação para trabalhar como atores. Como também é possível o trabalho dessas crianças como modelos, contratadas por agências de moda e de publicidade.

Entretanto, de acordo com o Estatuto da Criança e do Adolescente (BRASIL, 1990), no Art. 149, dispõe que compete à autoridade judiciária disciplinar, através de portaria, autorizar, mediante alvará, a participação de criança e adolescente em espetáculos públicos e concursos de beleza. Contudo, a autoridade deverá considerar as peculiaridades locais, a existência de instalações adequadas, a adequação do ambiente à eventual participação ou frequência de crianças e adolescentes, entre outras coisas.

Conforme entendimento da Justiça do Trabalho (BRASIL, 20I2) em relação ao tema, o posicionamento do juiz do Trabalho aposentado e professor de Direito Oris Oliveira afirma que "a complexidade é tão grande e os problemas emergentes tão delicados que não se pode se contentar com remeter-se às normas celetistas ou às genéricas do ECA", fazendo necessária uma "regulamentação elaborada com visão multidisciplinar da matéria".

Contudo, o mesmo ainda ressalta que a normatização não exclui a responsabilidade da família no acompanhamento dos menores que se aventuram na área artística. "Não se deve deduzir ser dispensável a atuação do poder-dever familiar a tudo que diga respeito ao trabalho dos filhos. Os pais devem previamente se informar sobre onde os filhos vão trabalhar, em que condições, assisti-los na celebração do contrato, exigir sua extinção se prejudicial a qualquer título."

A Convenção no 138 da Organização Internacional do Trabalho (OIT) preconiza e o Brasil ratifica que a idade mínima para o trabalho infantil é de dezesseis anos. No entanto, existe a possibilidade, ainda que excepcional, individual e específica para a admissão do trabalho artístico, que poderá ser para menores de 16 anos. Essa possibilidade necessita de licença ou alvará individual, o qual deverá definir em que atividades poderá haver o trabalho e quais as condições especiais.

\subsection{Trabalho Infantil Artístico}

O trabalho infantil tem crescido em todo o mundo, não sendo diferente no contexto brasileiro. Esse tipo de trabalho demonstra uma violação aos direitos humanos da criança e do adolescente. De acordo com Stefanoni (2016) o trabalho infantil no âmbito artístico tem sido cada vez mais comum, não só no Brasil, como em todo o mundo, porém, esse tipo de atividade, assim como todas as formas de trabalho infantil, representa uma violação dos direitos humanos da criança e adolescente. 
A forma de trabalho artística infantil representa uma quebra de muitos direitos essenciais das crianças e dos adolescentes que devem aproveitar ao máximo de suas fases para garantir um bom desempenho em etapas futuras, com liberdade para estudar, brincar, praticar esportes, longe de responsabilidades que não são condizentes com sua idade.

Porém, quando a pauta é o trabalho artístico infantil a visão da sociedade muda com relação ao tema do trabalho infantil. Se as crianças e adolescentes estiverem trabalhando na agricultura, em carvoarias, fábricas e minas representa uma violação aos seus direitos, entretanto, se estão trabalhando de forma artística, esse tipo de trabalho tem um valor diferenciado pela visão da sociedade.

Ver os seus filhos atrás de holofotes e sendo conhecidos pela sociedade é um sonho não apenas das crianças e adolescentes, mas também de muitos pais e responsáveis que imaginam um futuro com fama, glamour e altos salários. De fato, é muito estimulante para os pais verem os seus filhos brilharem na TV, cinema ou em passarelas de moda, não apenas pelo retorno financeiro, mas também pelo sucesso de seus descendentes, o que torna ainda mais difícil o combate desse tipo de trabalho pela legislação brasileira. Além disso, não temos no nosso ordenamento jurídico leis específicas que contemplem o tema. A aprovação dos pais ou responsáveis para a prática, faz com que torne ainda mais complicado a luta pelo trabalho infantil artístico.

Devemos levar em consideração a responsabilidades dessas crianças em assumir esse tipo de trabalho de forma tão precoce, deixando de lado suas brincadeiras e seu bem-estar com a família para assumir papéis em um ambiente de competição, onde a criança acaba por interiorizar uma visão de modelo padronizada pela sociedade, adquirindo hábitos que muitas vezes prejudica a sua própria saúde fisiológica e mental. Nesta senda, Josiane Rose Petry Veronese (2007) no diz que:

Crianças e adolescentes estão em processo especial de desenvolvimento. O trabalho precoce afeta diretamente o desenvolvimento físico e psicológico, ao sujeitá-los a esforços perigosos ou que vão além de suas possibilidades estruturais, resultando num pseudo-amadurecimento, pois anula a infância, a juventude e compromete as possibilidades de uma fase adulta saudável (VERONESE, 2007, p. 105).

Noutro giro, é preciso respeitar a idade certa para que as crianças possam assumir determinadas responsabilidades. De acordo com Marina Drosghic (2013) não cabe aos pais estabelecer se o seu filho, menor de 14 anos, pode ou não trabalhar na mídia televisiva. É preciso permitir que tenham o devido amparo inerente a sua peculiar condição de ser humano em desenvolvimento (físico, intelectual e emocional). Deste modo, os pais e responsáveis devem permanecer atentos e realizar investimentos em aprendizado educacional, para que possam evoluir de forma física e cognitiva, de modo tenham um desenvolvimento completo.

O fato é que grandes empresas possuem o poder de persuadir pais e responsáveis sob a promessa de auferirem muito dinheiro, tornando esse nicho de mercado cada vez mais competitivo, alimentado por sonhos de um público frágil que por muitas vezes sofrerão violações de seus próprios direitos, comprometendo o futuro de muitas crianças e adolescentes. Temos que levantar debates que objetivem mais atenção por parte do judiciário para que possam proteger cada vez mais os direitos de nossas crianças e adolescentes. 


\section{MÉTODO}

Este estudo caracteriza-se como uma pesquisa exploratória e descritiva, de cunho bibliográfico com uma revisão da literatura especializada com enfoque no trabalho infantil artístico na prerrogativa de proporcionar uma maior apreensão da questão apresentada e do problema elencado no presente estudo.

Nesse sentido, realizou-se consulta a artigos científicos selecionados através de busca no banco de dados do Scielo (Scientific Electronic Library Online), Google Acadêmico. A pesquisa dos artigos foi realizada entre outubro e novembro de 2020. As palavras-chave utilizadas na busca foram trabalho infantil artístico, desenvolvimento infantil, Constituição e ECA. Os critérios de inclusão para os estudos encontrados foram os que versam sobre o trabalho infantil artístico e/ou as consequências do trabalho infantil, com data de publicação entre os anos de 2010 a 2020.

\section{I Resultados e Discussão}

Os resultados serão apresentados em subseções, organizadas de acordo com as análises empregadas para o tratamento dos dados. Neste sentido, serão apresentados os dados do levantamento dos periódicos nos anos 2010-2020.

No que diz respeito aos periódicos e suas publicações na última década acerca da temática envolvendo o trabalho infantil artístico foram encontradas as seguintes publicações descritas abaixo conforme disposto no quadro I.

Quadro 1. Dados das publicações encontradas (2010-2020)

\begin{tabular}{|l|l|l|l|l|l|}
\hline Título & Autor & Revista & Ano & País & Fonte \\
\hline $\begin{array}{l}\text { O trabalho infantil } \\
\text { artístico e o limite de } \\
\text { dezesseis anos imposto } \\
\text { pela Constituição } \\
\text { Federal }\end{array}$ & $\begin{array}{l}\text { RIBEIRO, Márcia } \\
\text { Madeira Mauriz de }\end{array}$ & Repositório & 2012 & Brasil & Google \\
\hline $\begin{array}{l}\text { O trabalho da criança } \\
\text { na mídia televisiva }\end{array}$ & $\begin{array}{l}\text { DROSGHIC,Marin } \\
\text { a Silva Torquetti. }\end{array}$ & $\begin{array}{l}\text { Rev } \\
\text { Eletrônica de } \\
\text { Direito }\end{array}$ & 2013 & Brasil & $\begin{array}{l}\text { Google } \\
\text { Acadêmico }\end{array}$ \\
\hline $\begin{array}{l}\text { Trabalho Infantil } \\
\text { Contístico: } \\
\text { Legalidade e Limites }\end{array}$ & $\begin{array}{l}\text { CAVALCANTE, } \\
\text { Sandra Regina. }\end{array}$ & Revista TST & 2013 & Brasil & $\begin{array}{l}\text { Google } \\
\text { Acadêmico }\end{array}$ \\
\hline $\begin{array}{l}\text { Trabalho infantil: um } \\
\text { estudo sobre os danos } \\
\text { biopsicossociais } \\
\text { percebidos pelos } \\
\text { pesquisadores }\end{array}$ & $\begin{array}{l}\text { Martins; SOUZA, } \\
\text { Ricardo Luis V. de; } \\
\text { KIRST, Patrícia } \\
\text { Beatriz A. Gomes }\end{array}$ & Aletheia & 2015 & Brasil & Scielo \\
\hline
\end{tabular}




\begin{tabular}{|c|c|c|c|c|c|}
\hline $\begin{array}{lr}\text { Trabalho } & \text { Infantil } \\
\text { Artístico: } & \text { crianças } \\
\text { agenciadas } & \text { em } \\
\text { Florianópolis } & \end{array}$ & $\begin{array}{l}\text { PEREIRA, Agnes } \\
\text { Schveitzer }\end{array}$ & $\begin{array}{l}\text { Repositório } \\
\text { UFSC }\end{array}$ & 2015 & Brasil & $\begin{array}{l}\text { Google } \\
\text { Acadêmico }\end{array}$ \\
\hline $\begin{array}{l}\text { Trabalho infantil } \\
\text { artístico: a infância por } \\
\text { trás dos holofotes }\end{array}$ & $\begin{array}{l}\text { STEFANONI, } \\
\text { Luciana Renata } \\
\text { Rondina }\end{array}$ & $\begin{array}{l}\text { Âmbito } \\
\text { Jurídico }\end{array}$ & 2016 & Brasil & $\begin{array}{l}\text { Google } \\
\text { Academico }\end{array}$ \\
\hline $\begin{array}{l}\text { Competência para } \\
\text { (des) autorizar o } \\
\text { trabalho infantil }\end{array}$ & $\begin{array}{l}\text { OLIVA, José } \\
\text { Roberto }\end{array}$ & $\begin{array}{l}\text { Revista } \\
\text { Consultor } \\
\text { Jurídico }\end{array}$ & 2017 & Brasil & $\begin{array}{l}\text { Google } \\
\text { Acadêmico }\end{array}$ \\
\hline $\begin{array}{l}\text { Trabalho Artístico } \\
\text { Infanto-Juvenil: } \\
\text { Análise do caso MC } \\
\text { Pedrinho em Fortaleza }\end{array}$ & $\begin{array}{l}\text { LOIOLA, Juliana } \\
\text { Nogueira; JUNIOR, } \\
\text { Antonio } \quad \text { Jorge } \\
\text { Pereira }\end{array}$ & $\begin{array}{l}\text { Revista } \\
\text { Thesis Juris }\end{array}$ & 2018 & Brasil & $\begin{array}{l}\text { Google } \\
\text { Acadêmico }\end{array}$ \\
\hline $\begin{array}{l}\text { A controvérsia do } \\
\text { trabalho infantil } \\
\text { artístico: infração } \\
\text { constitucional ou } \\
\text { liberdade cultural? }\end{array}$ & $\begin{array}{l}\text { RAMOS, Paula } \\
\text { Orlandi. }\end{array}$ & $\begin{array}{l}\text { RIUNI, } \\
\text { Institucional } \\
\text { Repository }\end{array}$ & 2019 & Brasil & $\begin{array}{l}\text { Google } \\
\text { Acadêmico }\end{array}$ \\
\hline $\begin{array}{l}\text { O Trabalho Infantil } \\
\text { no Brasil como } \\
\text { Subtração de Direitos } \\
\text { Humanos e sua } \\
\text { Realação com o labor } \\
\text { forçado }\end{array}$ & $\begin{array}{l}\text { Schwartz, Germano; } \\
\text { Di Pasqua, Gabriela. }\end{array}$ & $\begin{array}{l}\text { Rev. do } \\
\text { Direito do } \\
\text { Trabalho e } \\
\text { Meio } \\
\text { Ambiente } \\
\text { do Trabalho }\end{array}$ & 2020 & Brasil & $\begin{array}{l}\text { Google } \\
\text { Acadêmico }\end{array}$ \\
\hline
\end{tabular}

Fonte: Dados da Pesquisa (PALITOT, et al, 2020)

No que diz respeito aos periódicos eletrônicos no período de 2010 a 2020, conforme disposto no quadro I, é possível perceber que existe uma boa produção acerca da temática abordada, porém, conforme alerta Stafanoni (2016) o trabalho artístico infantil, é um assunto presente no dia-a-dia de todos, e que muitas vezes, tem suas irregularidades camufladas por seu glamour ou sua valorização social, sendo ainda um assunto pouco discutido.

Marina Silva Torquetti Drosghic (2013) em seus estudos nos afirma que qualquer tipo de trabalho infantil deve ser proibido. Devendo prevalecer a idade mínima para o labor estipulada na Constituição, pois qualquer tipo de trabalho infantil prejudica na formação das crianças e adolescentes, pois retira do seu tempo o direito de estudar e brincar.

Já de acordo com Cavalcante (2013) ela defende em seu trabalho que a sociedade possa usufruir dos momentos de encanto e reflexão trazidos pela atuação de talentosos artistas 
mirins, porém de forma dosada. Pois, não se tem notícias de um país no qual seja proibida a participação de crianças nas produções artísticas e publicitárias e que a proibição geral e irrestrita pode prejudicar a quem justamente se deseja proteger. Entretanto, esse trabalho não deixa de ser um risco para a saúde das crianças e adolescentes, devendo ser acompanhados de medidas envolvendo normatização de restrições e fiscalização, campanhas educativas para informar a família, aos empresários e ao poder público do risco dessa atividade e que a escola possa contribuir como parceira social para denunciar qualquer excesso envolvendo as atividades artísticas do público infanto-juvenil.

O autor José Roberto Oliva (2017) em seu artigo concluiu que com relação a autorização ou desautorização do trabalho infantil não cabe autorização judicial para o trabalho antes da idade mínima prevista no artigo $7^{\circ}$, do inciso XXXIII, da Constituição Federal, salvo na hipótese do artigo 8oㅡ, in. I, da Convenção 138 da OIT e que a competência para a autorização judicial é da Justiça do Trabalho, e quando indeferida a petição inicial ou indeferido de plano o pedido, o juiz do Trabalho observará o disposto no artigo 22I do ECA. Destacou que a competência material para conhecer e decidir sobre a autorização para o trabalho da criança e do adolescente é da Justiça do Trabalho, lembrando que a competência é mais para desautorização de trabalho infantil, inclusive artístico.

Juliana Nogueira Loiola e Antônio Jorge Pereira Júnior (2018) em seu trabalho tratando de um caso específico, do menor MC Pedrinho, defende a necessidade de uma intervenção estatal na proteção do público infanto-juvenil, durante suas manifestações artísticas, quando estes não são acompanhados pela família de maneira precedente, de forma que se priorize a criança e o adolescente em sua dignidade.

Stefanoni (2016) em seus relatos conclui que a sociedade enxerga o trabalho infantil artístico como algo normal, que está ligado a padrões de fama, prestígio. Até artistas circenses mirins que se apresentam nos sinais de trânsito fazendo malabarismo, são vistos com bons olhos pela sociedade, que adotam a falsa ideia de que é melhor aquele menor estar fazendo malabares nas ruas, do que roubando, assaltando ou se prostituindo.

\section{${ }_{4}$ CONSIDERAÇÕES FINAIS}

O presente artigo teve como objetivo analisar à luz do ordenamento jurídico brasileiro qual o entendimento acerca do trabalho infantil artístico de criança e/ou adolescente. Frente a isto, buscou-se na literatura vigente o que se havia produzido ao logo das duas últimas décadas em relação ao trabalho infantil artístico. Foram encontrados um bom número de trabalho referente a temática, porém, ainda é nítida a lacuna de trabalhos que relatem as consequências oriundas dos trabalhos infantis artísticos para o desenvolvimento infanto-juvenil.

Mesmo com mecanismos legais para impedir a realização de trabalho infantil no Brasil, a presença de crianças e adolescentes em ocupações laborais impróprias é ainda uma realidade no país. Mais do que isso, a maneira como a legislação brasileira foi formulada quanto à questão do trabalho realizado por menores, acabou por deixar brechas que possibilitam a realização do trabalho infantil artístico. Entende-se aqui que o trabalho infantil artístico não é uma atividade inerentemente ruim, e que os jovens têm o direito de expressar-se artisticamente e até receber remuneração por tal, no entanto, faz-se necessária especial atenção, fiscalização e regulamentação de tal matéria de maneira que o bem-estar 
físico e psicológico da criança ou adolescente em questão seja preservado, e prevaleça sobre qualquer ganho econômico.

Essa fiscalização faz-se necessária para se evitar relatos como o trazido por Raquel Marques (2017) sobre o filme "Cidade de Deus", na qual retrata a cena vivida pelo ator Filipe Paulino com oito anos na época, dirigido por Fernando Meirelles e lançado em 2002. Para Marques (2017) não foi ao acaso, que ela foi eleita como a mais violenta da história do cinema pelo site especializado Pop Crunch. Se as imagens já são chocantes para o espectador, o episódio jamais será esquecido pelo ator mirim.

Marques nos afirma que o ator Felipe Paulino, na época com 8 anos, conta que o trauma após interpretar o menino atingido o perseguiu até a adolescência. Mesmo tendo visto o filme várias vezes, só conseguiu assistir ao trecho descrito acima quando completou I8 anos. "Filmar aquela cena foi um dos grandes traumas da minha vida. A preparadora de elenco fazia uns exercícios muito loucos para que eu tivesse medo do Leandro Firmino (ator que interpretou o personagem Zé Pequeno). A gente não podia almoçar junto, me deixavam em um quarto escuro, acendiam a luz de repente e o Leandro estava lá. Aquilo ficou na minha mente por muito tempo" (Felipe Paulino).

Frente ao exposto, percebe-se que o ordenamento jurídico brasileiro deveria se posicionar em relação a certos enredos, e não temer por questões de censura, mas sim procurar proteger a infância das suas crianças. Trabalhos como o relatado acima, trazem consequências às vezes irreparáveis ao desenvolvimento infanto-juvenil. Ressaltamos a necessidade urgente de trabalhos e de políticas públicas que venham assegurar os direitos humanos daqueles que são indefesos e que na maioria das vezes usados como fonte de renda e/ou meios para se atingir a fama.

Reiteramos que é dever conjunto do Estado, da família e da sociedade em geral, zelar pela proteção aos direitos básicos da criança e do adolescente, como a educação, o lazer e a saúde, em qualquer contexto, tendo sempre em mente que o trabalho artístico, por mais adornado que seja, em especial nos dias atuais, continua sendo mais uma forma de trabalho, e quando realizado de maneira imprudente pode se configurar como exploração. Não esqueçamos que crianças e adolescentes talentosos artisticamente, continuam a ser tão somente crianças e adolescentes, e não devem ter sua infância privada para geral de dinheiro.

\section{REFERÊNCIAS}

ALMEIDA, Patrícia Madeira Mauriz de. O Trabalho Infantil Artístico e o Limite de Dezesseis anos Imposto pela Constituição Federal. Monografia apresentada como requisito parcial à obtenção do título de Especialista em Direito e Processo do Trabalho, no Curso de Pós-graduação Lato Sensu em Direito do Trabalho e Processo do Trabalho, no Instituto Brasiliense de Direito Público-IDP. 2011.

BRASIL. Decreto 10.088/2019. Disponível em: http://www.planalto.gov.br/ccivil_03/_Ato2019-2022/2019/Decreto/Dioo88.htm\#art5

. Consolidação das leis do trabalho - CLT e normas correlatas. - Brasília: Senado

Federal, Coordenação de Edições Técnicas, 2017.

. Estatuto da Criança e do Adolescente. Lei no 8069, de I3 de julho de 1990. 


\section{Constituição Federal de $1988 . \quad$ Disponível}

em:

https://www.senado.leg.br/atividade/const/conı988/conı988_o6.o6.2017/ind.asp

CAMPOS, Herculano Ricardo; FRANCISCHINI, Rosângela. Trabalho infantil produtivo e desenvolvimento humano. Psicol. estud. , Maringá, v. 8, n. I, pág. II9-I29, junho de 2003. Disponível em $\quad$ http://www.scielo.br/scielo.php?script=sci_arttext\&pid=Si41373722003000100015\&lng=en\& $\mathrm{nrm}=$ iso $>$ https://doi.org/10.1590/SI413-73722003000100015

CARVALHO, Regina Coelli Batista de Moura. Idade e trabalho: abordagem sócio-jurídica sobre limitação de idade para o trabalho no Brasil. Porto Alegre: Sergio Antonio Fabris Editor, 2004, p. 5 I.

CAVICCHIA, Durlei de Carvalho. O Desenvolvimento da Criança nos Primeiros Anos de Vida. Psicologia do Desenvolvimento. 2oro. Disponível em: https://acervodigital.unesp.br/bitstream/123456789/224/ı/ordıItor.pdf

COSTA, Elenise Martins; SOUZA, Ricardo Luis Vieira de; KIRST, Patrícia Beatriz Argollo Gomes. Trabalho infantil: um estudo sobre os danos biopsicossociais percebidos pelos pesquisadores. Aletheia, Canoas, n. 46, p. I3I-I4I, abr. 2015. Disponível em http://pepsic.bvsalud.org/scielo.php?script=sci_arttext\&pid=SI4I3-

0394201500o10oor \&lng=pt\&nrm=iso

DROSGHIC, Marina Silva Toquetti. O trabalho da Criança na Mídia Televisiva. Revista Eletrônica de Direito, 2013.

MARCHI, Rita de Cassia. Trabalho infantil: representações sociais de sua instituição em Blumenau/SC. Educ. rev., Curitiba, n. 47, p. 249-265, Mar. 2013. Available from $<$ http://www.scielo.br/scielo.php?script=sci_arttext\&pid=Soro44060201300o10oor3\&lng=en\&nrm =iso $>$ http://dx.doi.org/10.1590/So104-4060201300o10oor3.

MARQUES, Raquel. Os limites do trabalho infantil artístico. Rede Peteca. 2017. Disponivel em: https://www.chegadetrabalhoinfantil.org.br/noticias/materias/os-limites-trabalhoinfantil-artistico/

MENNA, Lígia Regina Máximo Cavalari. Diferentes concepções de infância na literatura. Revista crioula, 2010.

PAPALIA, D. E.; FELDMAN, R. D. Desenvolvimento Humano. I2.ed.Porto Alegre: AMGH, 2013.

STEFANONI, Luciana Renata Rondina. Trabalho infantil artístico: a infância por trás do holofote. Âmbito Jurídico. 2016.

VERONESE, Josiane Rose Petry; CUSTÓDIO, André Viana. Trabalho infantil: a negação do ser criança e adolescente no Brasil. Florianópolis: OAB/SC Editora, 2007. 
VIGOTSKY, Lev Semenovich. A Formação Social da Mente: O Desenvolvimento dos Processos Psicológicos Superiores. Trad. José Cipolla Neto, Luís Silveira Menna Barreto, Solange Castro Afeche. 6ae ed. São Paulo: Martins Fontes, 1998.

A difícil tarefa na regulamentação do trabalho infantil artístico. Justiça do Trabalho, 2012. Disponível em < http://www.tst.jus.br/noticias/-/asset_publisher/89Dk/content/adificil-tarefa-na-regulamentacao-do-trabalho-infantil artistico\#: :text=Flexibiliza\%C $3 \% \mathrm{~A}_{7 \%} \mathrm{C}_{3 \%}$ A30\%2opara\%2otrabalho\%20art\%C3\%ADstico, aprendiz\%2C\%20a\%2opartir\%20dos\%2014>. 